\title{
MOBILIZAÇÃO DO CONHECIMENTO SOCIOAMBIENTAL DE PROFESSORES POR MEIO DO DESENVOLVIMENTO DE ACְÕES PARA CONSERVAÇÃO DE NASCENTES URBANAS
}

\author{
Catarina Teixeira* \\ Jacqueline Magalhães Alves**
}

RESUMO: A pesquisa teve como objetivo desenvolver um trabalho compartilhado com professores da educação básica sobre questões socioambientais locais e analisar o processo de interação, reflexão e elaboração pelos sujeitos participantes da pesquisa, cujo tema mobilizador teve foco na conservação e na preservação de nascentes. Os instrumentos de coleta de dados foram: audiogravação de todos os encontros, diário de campo da pesquisadoras, questionários abertos e registros escritos pelos professores. A análise dos dados decorrente dos encontros se baseou na metodologia denominada Análise de Conteúdo. Observamos uma maior interação dos professores com o tema da pesquisa quando eles se apropriaram do tema e o relacionaram com a problemática socioambiental local.

Palavras-chave: Educação Ambiental. Formação de Professores. Problemática socioambiental local.

\section{MOBILIZACIÓN DEL CONOCIMIENTO SOCIO-AMBIENTAL DE PROFESORES A PARTIR DEL DESARROLLO DE ACCIONES PARA CONSERVACIÓN DE NACIENTES URBANAS}

RESUMEN: La investigación tiene el objetivo de desarrollar un trabajo compartido con los profesores de educación básica acerca de cuestiones socio-ambientales locales y analizar el proceso de interacción, reflexión y elaboración por los sujetos participantes de la investigación, cuyo tema movilizador tuvo foco en la conservación y la preservación de nacientes. Los instrumentos de colección de datos fueron: audio-grabación de todos los encuentros, diario de campo de la investigadora, cuestionarios abiertos y registros escritos por los profesores. El análisis de los datos que partieron de los encuentros se basó en la metodología del Análisis de Contenido. Observamos interacción más grande entre los profesores con el tema de la investigación cuando ellos se apropiaron del tema y lo relacionaron con la problemática socio-ambiental local.

Palabras clave: Educación ambiental. Formación de profesores. Problemática socio-ambiental local 
TEACHER'S SOCIAL-ENVIRONMENTAL KNOWLEDGE MOBILIZATION THROUGH THE DEVELOPMENT OF ACTIONS FOR URBAN SPRINGS' CONSERVATION

ABSTRACT: This research aimed to develop a shared work with basic education teachers about local socio-environmental issues and analyze the process of interaction, reflection and preparation by subjects participating in the survey. The subject's mobilizing theme was focused on conservation and preservation of springs. The tools used for data collection were: audio recording of all the meetings, field diary of the researcher, open questionnaires and reports written by the teachers. The analysis of data from the meetings was based on the methodology called Content Analysis. We observed teachers' higher interaction with the theme of the research when they made the theme relevant and related it to their local socio-environmental issue. Keywords: Environmental Education. Formation of teachers. Local Socio-environmental Problem. 


\section{INTRODUÇÃO}

As questões ambientais, cada vez mais, têm ocupado a agenda de diferentes setores da sociedade e se tornado a preocupação de vários educadores. Ainda que por meio de diferentes concepções teórico-metodológicas essas questões venham sendo discutidas, o encaminhamento dessa temática pela escola só se materializou oficialmente a partir de 1997, por intermédio dos Parâmetros Curriculares Nacionais (PCN), coordenados e propostos pela Secretaria de Ensino Fundamental do então Ministério de Educação e do Desporto. Desse modo, de acordo com Rosa (2003), nos PCNs é apresentada a proposta de que os professores de todas as áreas contemplem a discussão da temática ambiental em suas respectivas disciplinas ou em projetos, sem, contudo, trabalhar o tema isoladamente.

Segundo Rosa (2003), a temática ambiental vem ganhando espaço nas escolas, em decorrência da importância de se rever a relação do ser humano com o meio em que vive. Políticas educacionais são propostas com o objetivo de trabalhar a Educação Ambiental (EA) como tema transversal na escola, visando suprir as lacunas até então encontradas.

A Educação Ambiental são os processos por meio dos quais o indivíduo e a coletividade constroem valores sociais, conhecimentos, habilidades, atitudes e competências voltadas para a conservação do meio ambiente, bem de uso comum do povo, essencial à sadia qualidade de vida e sua sustentabilidade (BRASIL, 1999).

De acordo com Pontalti (2005), a escola é o espaço social e o local onde o aluno dará sequência ao seu processo de socialização, iniciado em casa, com seus familiares. Assim, é evidente a importância da escola no processo de formação, tanto social quanto ambiental, de estudantes, professores e comunidade em geral.

Desse modo, a escola, ao propor o desenvolvimento de um currículo voltado para a questão ambiental, deve proporcionar a participação de toda a comunidade escolar no processo de construção e implementação. Os conteúdos escolares precisam ser revistos para que os mesmos se organizem em torno de temas geradores de uma aprendizagem interdisciplinar, relevante e comprometida com questões ambientais de âmbito local e global. A Educação Ambiental pode ser entendida como um importante eixo integrador/articulador do currículo escolar, na busca de um conhecimento que supere a usual fragmentação, com vistas à emancipação dos sujeitos. Assim, a EA apresenta-se como uma peça importante no currículo escolar, pois envolve, de maneira integrada, os aspectos físicos, biológicos, sociais e culturais da sociedade.

Nessa perspectiva, foi aprovado, no âmbito do Edital FAPEMIG CAPES 13/2012 - Pesquisa na Educação Básica, o projeto "Adolescência e juventude na relação com o ambiente: conhecer e cuidar como princípio de identidade e pertencimento" (Projeto AJA), que está sendo desenvolvido em uma escola da rede pública estadual no município de Lavras, MG. O projeto tem como objetivo central estimular a participação dos estudantes e professores do ensino médio dessa escola em projetos de formação e intervenção na escola, na comunidade do entorno da escola e no município, integrando educação-trabalho, conhecimento socioambiental e a consolidação/ 
construção de identidades culturais.

A equipe desse projeto, da qual as autoras dessa pesquisa são integrantes, iniciou seus trabalhos em agosto de 2013. Uma das primeiras atividades dessa equipe foi a análise do Projeto Político Pedagógico (PPP) da Escola e também o levantamento de informações a partir de questionários realizados com 17 professores, durante reunião de apresentação do projeto na Escola. Nesses dois momentos, constatamos que várias atividades de Educação Ambiental já haviam sido desenvolvidas na Escola, tais como: oficina de reciclagem, coleta seletiva de lixo, confecção de folder sobre pilhas usadas, dentre outras atividades. Por outro lado, verificamos a ausência de outras temáticas relevantes, como questões relacionadas à água, que necessitam ser trabalhadas devido à crise da água vivida atualmente pela humanidade.

A água pode ser considerada o elemento mais precioso da vida na Terra, satisfazendo todas as necessidades básicas dos seres humanos, dentre elas a saúde, a produção de alimentos e a permanência dos ecossistemas. Essa importância, associada à sua escassez, faz com que a conservação e a recuperação das nascentes de água sejam instrumentos essenciais para a qualidade de vida de todos, até mesmo das futuras gerações em nosso planeta.

As nascentes abastecem os riachos, córregos e cursos d'água que, por sua vez, abastecem os rios. Se não houver a proteção das nascentes, menor será a vazão de água disponível, os cursos d’água podem secar, e a qualidade das águas será prejudicada, afetando todos os seres vivos que dependem dela para sobreviver.

Um levantamento realizado no município de Lavras pela Organização Não Governamental (ONG) Movimento Ecológico Verde Vida de Lavras mostra que há mais de cinquenta nascentes no distrito urbano da cidade, sendo precária a situação de muitas dessas nascentes, com acúmulo de lixo e total degradação de seu entorno (SANTOS, 2013).

Considerando a importância das nascentes para a manutenção da qualidade de vida das pessoas e a relevância do tema Meio Ambiente, esta investigação traz subsídios para a elaboração de um trabalho interdisciplinar cujo foco é a sensibilização da comunidade escolar no desenvolvimento de uma conscientização a respeito da importância e conservação/preservação das nascentes urbanas do município de Lavras, MG.

Tomando como referência a problemática socioambiental local, apresentamos a questão norteadora desta pesquisa: Quais elaborações ${ }^{1}$ são produzidas por professores da escola pública ao participarem da construção de um projeto cujo tema articulador é um problema socioambiental local?

Com isso, temos como objetivo desenvolver um trabalho compartilhado com professores da educação básica sobre questões socioambientais locais e analisar o processo de interação, reflexão e elaboração pelos sujeitos participantes da pesquisa. O tema mobilizador teve como foco a conservação e preservação de nascentes, a fim de contribuir para o processo de conscientização e constituição de identidades e responsabilidades individuais/coletivas na Escola e na comunidade escolar.

Buscaremos identificar como se desenvolvem as interações dos sujeitos em um processo orientado por ações interdisciplinares; investigar a relação que os docen- 
tes da educação básica estabelecem com os saberes mobilizados na construção de uma proposta de trabalho para a preservação das nascentes e subsidiar e analisar a produção e o desenvolvimento de atividades que contribuam com o processo de conscientização da comunidade escolar sobre a importância e a recuperação/conservação/preservação das nascentes urbanas.

Embora a temática de pesquisa aqui selecionada - isto é, a Educação Ambiental - venha sendo investigada, nas últimas décadas, por inúmeros autores, tais como Guimarães (2004), Carvalho (2005), Loureiro (2004, 2005, 2007), Oliveira (2007), Reigota (2007), entendemos que a presente investigação traz uma abordagem ainda pouco explorada na área, privilegiando compreender a elaboração de uma atividade que visa envolver diferentes disciplinas em um processo de formação continuada de professores com o foco na problemática socioambiental local.

A formação e o trabalho docente é uma questão importante uma vez que ele deve estar consciente de que sua formação deve ser contínua e está relacionada ao seu dia a dia. A formação de professores é a estratégia básica para o desenvolvimento de práticas de Educação Ambiental definidas na Política Nacional de Educação Ambiental:

\20 A capacitação de recursos humanos voltar-se-á para:

I - a incorporação da dimensão ambiental na formação, especialização e atualização dos educadores de todos os níveis e modalidades de ensino;

II - a incorporação da dimensão ambiental na formação, especialização e atualização dos profissionais de todas as áreas.

(BRASIL,1999, artigo 8)

Afinal, frente a qualquer proposta inovadora de ensino, assim como parece ser a proposta da EA, devemos refletir sobre elementos essenciais para sua efetivação: o professor e a sua formação.

\section{Referenciais teóricos}

A Educação Ambiental deve ser uma educação crítica e transformadora, capaz de incentivar o desenvolvimento de valores e atitudes que possibilite a inserção dos sujeitos da educação em processos democráticos de transformação das modalidades de uso dos recursos naturais e sociais.

De acordo com Guimarães (2004), a EA Conservadora reproduz a ideologia e os valores do próprio sistema no qual estamos inseridos, que, na opinião desse autor, são os pilares da crise ambiental:

Esta Educação ambiental tradicional, não pode e/ou não quer perceber as redes de poder que estruturam as relações de dominação presentes na sociedade atual, tanto entre pessoas (relações de gênero, de minorias étnicas e culturais), entre classes sociais, quanto na relação norte-sul entre nações, assim como também entre relações de dominação que se construíram historicamente entre sociedade de natureza. São nessas relações de poder e dominação que podemos encontrar um dos pilares da crise ambiental dos dias de hoje. (GUIMARÃES, 2004 p. 35) 
Loureiro (2007) destaca a importância da Educação Ambiental Crítica, que incentiva a problematização da realidade, de nossos valores, atitudes e comportamentos em práticas dialógicas.

É importante compreender que um dos eixos sobre os quais se assenta a Educação Ambiental crítica é a capacidade de mobilização social de modo a possibilitar a participação efetiva, pois

\begin{abstract}
objetiva promover ambientes educativos de mobilização desses processos de intervenção sobre a realidade e seus problemas socioambientais, para que possamos nestes ambientes superar as armadilhas paradigmáticas e propiciar um processo educativo, em que nesse exercício, estejamos, educandos e educadores, nos formando e contribuindo, pelo exercício de uma cidadania ativa, na transformação da grave crise socioambiental que vivenciamos todos. (GUIMARÃES, 2004, p. 30-31)
\end{abstract}

Entre várias formas possíveis de se trabalhar a Educação Ambiental crítica, os Parâmetros Curriculares Nacionais e a Política Nacional de Educação Ambiental afirmam a interdisciplinaridade como essencial ao desenvolvimento de temas ligados ao Meio Ambiente, sendo necessário desfragmentar os conteúdos e reunir as informações dentro de um mesmo contexto, nas várias disciplinas. Um dos modos de se trabalhar a interdisciplinaridade são os projetos de Educação Ambiental, que podem e devem ser desenvolvidos nas escolas a fim de fomentar a criatividade e o raciocínio dos alunos, por meio de atividades dinâmicas e participativas, relacionando teoria e prática.

Numa breve explicação, Reigota (2009) diz que uma prática pedagógica interdisciplinar trabalha com diálogo de conhecimentos disciplinares.

Santos e Compiani (2005) afirmam que, no momento em que a interdisciplinaridade rompe as barreiras entre as diferentes áreas do saber, ela provoca uma postura epistemológica frente ao conhecimento. Isso pressupõe um diálogo entre saberes, uma integração de conhecimentos visando a novos questionamentos, novas buscas, enfim, à transformação da própria realidade.

De acordo com Charlot (2000), não há saber senão para um sujeito, não há saber senão organizado de acordo com relações internas, não há saber senão produzido em uma “confrontação interpessoal". Em outras palavras, a ideia de saber implica a de sujeito, de atividade do sujeito, de relação do sujeito com ele mesmo, de relação desse sujeito com os outros (que constroem, controlam, validam, partilham esse saber).

A relação com o saber é relação de um sujeito com o mundo, com ele mesmo e com os outros. É relação com o mundo como conjunto de significados, mas, também, como espaço de atividades que se inscreve no tempo (CHARLOT, 2000).

Essa relação está presente nos processos da educação, como na Educação Ambiental, que é uma prática pedagógica, "essa prática não se realiza sozinha, mas nas relações do ambiente escolar, na interação entre diferentes atores, conduzida por um sujeito, os educadores" (GUIMARÃES, 2012, p. 38). 


\section{O percurso metodológico da pesquisa}

A concretização dessa pesquisa ocorre por meio de uma investigação de abordagem qualitativa, pois nela "a preocupação do pesquisador não é com a representatividade numérica, mas com o aprofundamento da compreensão de um grupo social (...)" (GOLDENBERG, 1999, p. 14), em uma trajetória de formação em que se busca mobilizar os saberes docentes em um contexto de mudanças nas orientações curriculares que nos colocam o desafio de repensar a convencional organização disciplinar do currículo e a inserção das questões de diversidade cultural e social no processo de formação do cidadão contemporâneo.

De acordo com Longarezi e Silva (2008), a formação continuada de professores, especialmente nas três últimas décadas, tem ocupado uma posição de centralidade no contexto educacional, figurando como um dos temas de pesquisa mais recorrentes. Como resultado do grande interesse desenvolvido em torno dessa temática, muitas pesquisas têm despontado como propostas de formação contínua de professores, mediante metodologias científicas que colocam o profissional docente como sujeito desse processo.

Nesse sentido, as relações entre pesquisa e profissão podem abranger um vasto leque de atividades e de projetos, contanto que estes estejam realmente embasados na vivência profissional dos professores. É nessa perspectiva que se desenvolvem, atualmente, práticas de pesquisa (pesquisa colaborativa, pesquisa ancorada, pesquisa-ação, pesquisa em parceria, etc.) nas quais os professores tomam parte: o prático torna-se um co-parceiro dos pesquisadores. As fronteiras entre o pesquisador e o professor tendem a se apagar ou pelo menos a se deslocar, proporcionando o surgimento de novos atores: o professor-pesquisador, o pesquisador integrado na escola, etc. (TARDIF, 2005, p. 293)

Com isso, a investigação qualitativa é constituída por diversos métodos, bem característicos dessa abordagem. Nesse universo da pesquisa qualitativa, optamos por desenvolver uma investigação inspirada em pressupostos da pesquisa-ação, devido à intencionalidade da pesquisadora no trabalho de formação compartilhada realizado com os professores. Embora não se esteja realizando uma pesquisa-ação propriamente dita, especialmente pelo fato de a questão temporal estar comprometida ${ }^{2}$, encontramos tais pressupostos em definições de pesquisa-ação dadas por alguns autores: Thiollent (1985, 2005); Sato (1997); Tozoni-Reis (2005) e Santos (2010).

Sato (1997) considera esse método o mais indicado para pesquisas em Educação Ambiental por permitir a participação dos envolvidos por meio de reflexões críticas de um problema percebido por todos, potencializando a emancipação e a participação social. A autora destaca ainda que a pesquisa-ação está sendo amplamente difundida e utilizada nos grandes projetos realizados em diversos países europeus onde professores são estimulados a desenvolver atividades em Educação Ambiental em suas escolas.

Desse modo, concordamos com Santos (2010), que diz que a pesquisa-ação contém elementos que contribuem para a formação do professor crítico e reflexivo para a construção do conhecimento escolar, orientados por práticas emancipatórias. 
O processo de pesquisa foi iniciado na Escola com a permissão da direção escolar para que a pesquisadora, autora desta pesquisa, se reunisse uma vez por semana com o maior número de professores que aceitassem participar da pesquisa e cumprissem a carga horária de Módulo $\mathrm{II}^{3}$ no mesmo horário. Verificou-se junto aos professores e à direção o horário que concentrava o maior número de professores com interesse em participar da pesquisa. Com isso, chegamos a quatro professoras que cumprem sua carga horária de Módulo II no mesmo momento.

As quatro professoras participantes da pesquisa lecionam disciplinas diferentes: Geografia, História, Ciências e Biologia, cada uma com uma dessas disciplinas. Os encontros com as professoras tiveram a duração de aproximadamente 50 minutos, sendo esse o tempo disponibilizado, pois algumas tinham aula após os encontros.

Foram realizados sete encontros; cada encontro foi pensado e repensado, ou seja, o grupo de professoras planejava e replanejava os materiais que seriam trabalhados, em função das respostas, envolvimento e reflexões do coletivo, ou seja, das professoras e pesquisadora a cada encontro, pois, de acordo com Santos (2005, p. 147) "a participação coletiva é condição fundante da pesquisa-ação. Não há pesquisa-ação sem participação coletiva”.

Para a composição dos dados desta pesquisa, foram utilizados os seguintes instrumentos: audiogravações realizadas durante os encontros com as professoras da Escola, seus registros escritos, questionários abertos e as anotações contidas no Diário de Campo da pesquisadora.

Os instrumentos escolhidos para a captação dos dados puderam trazer informações convergentes, ou então dados que se complementam uns aos outros e buscam reunir informações sobre o objeto de investigação no contexto natural no qual está situado, considerando toda a sua complexidade.

Após as transcrições, leitura dos questionários e anotações feitas pela pesquisadora no Diário de Campo, buscamos: i) identificar como se desenvolveram as interações dos sujeitos em um processo orientado por ações interdisciplinares; ii) investigar a relação que docentes da educação básica estabelecem com os saberes mobilizados na construção de uma proposta de trabalho para preservação das nascentes, e iii) subsidiar e analisar a produção e o desenvolvimento de atividades que contribuam com o processo de conscientização da comunidade escolar sobre a importância da recuperação/conservação/preservação das nascentes urbanas. Com o intuito de manter sigilo sobre o nome das participantes da pesquisa, essas são nomeadas de P1 a P4.

A pesquisadora confrontou as informações na tentativa de identificar e compreender melhor os pontos de confluência, os quais podem surgir como categorias de análise, conferindo maior credibilidade à pesquisa.

O aporte teórico para a análise configurou-se à luz dos dados, os quais nos encaminham para uma reflexão teórica sobre a Educação Ambiental e as 
concepções de aprendizagem da docência ${ }^{4}$, a partir de uma metodologia denominada Análise de Conteúdo (FRANCO, 2005; BARDIN, 2008).

A escolha da Análise de Conteúdo para analisar os dados produzidos pela pesquisa se deu devido à possibilidade de produzir inferências acerca de dados verbais e/ou simbólicos, obtidos a partir de perguntas e observações de interesse do pesquisador (FRANCO, 2005).

Bardin (2008, p. 38) define a Análise de Conteúdo "como um conjunto de técnicas de análise das comunicações, que utiliza procedimentos sistemáticos e objetivos de descrição do conteúdo das mensagens". Porém, a própria autora admite que essa definição não é suficiente. O interesse nessa metodologia não reside propriamente na descrição dos conteúdos da mensagem, "mas sim no que estes nos poderão ensinar após tratados" em comparação com "outras coisas". Complementando sua definição, a autora coloca em evidência a finalidade de qualquer análise de conteúdo, a inferência. Desse modo, "a intenção da análise de conteúdo é a inferência de conhecimentos relativos às condições de produção (ou, eventualmente, de recepção), inferência esta que recorre a indicadores (qualitativos ou não)" (BARDIN, 2008, p. 38). A inferência é tida como o procedimento intermediário, que permite a passagem explícita e controlada de duas etapas fundamentais dessa metodologia: "a descrição (a enumeração das características do texto, resumida após tratamento)"; e "a interpretação (a significação concedida a essas características)" (BARDIN, 2008, p. 39).

A maioria dos procedimentos de análise qualitativa organiza-se em torno de categorias, que podem ser rubricas ou classes que reúnem um grupo de elementos em razão de características comuns.

Para escolher categorias, vários critérios podem ser considerados: semântico (temas), sintático (verbos, adjetivos, pronomes), léxico (juntar pelo sentido das palavras, agrupar os sinônimos, os antônimos), expressivo (agrupar as perturbações da linguagem, da escrita).

A categorização permite reunir maior número de informações à custa de uma esquematização e assim correlacionar classes de acontecimentos para ordená-los. A categorização representa a passagem dos dados brutos a dados organizados.

Para identificar as categorias, foram definidas unidades de registro e unidades de contexto. Foram considerados unidades de registro os temas que contribuem para a criação das categorias. As unidades de contexto são os parágrafos ou segmentos da mensagem, utilizados como unidades de compreensão para identificar os temas definidos como unidades de registro. 
QUADRO 1 - Síntese do processo de construção das categorias

\begin{tabular}{|l|l|}
\hline Tema & \multicolumn{1}{c|}{ Observações para o agrupamento } \\
\hline \multirow{5}{*}{ Relação com o saber interdisciplinar } & $\begin{array}{l}\text { Notamos as dificuldades das professoras } \\
\text { ao elaborar uma atividade que, de fato, } \\
\text { fosse interdisciplinar, mostrando uma con- } \\
\text { tradição entre teoria e prática sobre um } \\
\text { projeto interdisciplinar, na prática, ou seja, } \\
\text { ao propor uma atividade interdisciplinar, } \\
\text { as professoras sugeriram inicialmente uma } \\
\text { atividade fragmentada; porém, ao descre- } \\
\text { verem o termo interdisciplinar, mostraram } \\
\text { saber, na teoria, o que realmente seria inter- } \\
\text { disciplinaridade. }\end{array}$ \\
\hline Pertencimento & $\begin{array}{l}\text { Determinado conforme observações do } \\
\text { envolvimento e interesse das professoras } \\
\text { pela atividade desenvolvida por elas e } \\
\text { uma maior participação das professoras } \\
\text { no decorrer dos encontros. }\end{array}$ \\
\hline
\end{tabular}

Dessa análise, emergiram as seguintes categorias:

- Relação com o saber interdisciplinar

-Pertencimento

\section{Discussão dos resultados}

Mediante a leitura e releitura das transcrições dos encontros, dos questionários e do Diário de Campo, verificamos um processo de mudança das professoras ao longo dos encontros. Isso foi percebido devido ao maior envolvimento com a pesquisa, reconhecimento das nascentes como uma problemática socioambiental local, e interesse pela proposta interdisciplinar desenvolvida por elas.

Essas observações subsidiaram a realização da categorização a partir da semântica, devido à relação com o saber interdisciplinar, no qual se mostra a contradição entre a teoria e a prática, na elaboração de uma atividade interdisciplinar e a construção de pertencimento da relação com o tema nascentes, na elaboração de uma atividade interdisciplinar gerada ao longo dos encontros. Essas situações foram tomadas como categorias de análise dessa investigação. 


\section{Relação com o saber interdisciplinar}

Essa categoria emergiu dos dados quando as professoras definiram o termo, mas elas demonstraram divergências entre a teoria e a prática ao esboçar uma atividade interdisciplinar, cujo tema gerador pertencesse ao contexto da Educação Ambiental.

Durante os encontros, indagamos sobre a possibilidade de pensarmos um trabalho que envolvesse todas as disciplinas, ou seja, um trabalho interdisciplinar sobre as nascentes. Duas professoras responderam:

QUADRO DE CONTEÚDO 1 - Sugestão da atividade interdisciplinar

P1: 'É possivel, a gente, por exemplo, a gente podia, eles podiam detectar através de fotos, pegavam essas fotos na internet, ai depois, por exemplo, a professora de português pedia um folder, a de geografia pedia a localização dentro do mapa onde é que tava esses espaços."

\section{P2: "Fazer uma maquete."}

P1: "Vai detectar, por exemplo, se historicamente o terreno sempre foi assim, se pertenceu sempre a uma pessoa só, por que hoje virou um loteamento e tem essa nascente lá nele, na biologia a importância dessa nascente pro meio ambiente pra própria fisiologia, e ai vai. A educação física o que podia ser pra ta ligada com essa nascente? É importante essa nascente pro esporte. Vai beneficiar alguém, não, mas a água é essencial, e aí vai."

Percebemos que as professoras, nesse momento, pensam em uma atividade com cada disciplina fazendo uma parte, sem nenhuma contextualização na escola sobre as nascentes. De acordo com Guimarães (2012), essa visão fragmentária potencializa uma forte tendência ao desenvolvimento, nas escolas, de ações isoladas, voltadas para o comportamento de cada indivíduo (aluno), e às vezes descontextualizadas da realidade socioambiental em que a escola está inserida.

É necessário, na construção de uma atividade interdisciplinar, que, além de trabalharmos uma problemática socioambiental local, envolvermos todos na construção da atividade. Sendo assim, todos devem ter conhecimento do assunto a ser tratado e desenvolver ações conjuntas; mesmo que, em alguns momentos, os professores vislumbrem, em sua disciplina, um determinado conteúdo da atividade interdisciplinar, eles não irão fragmentar o tema, afinal, segundo Milton Santos (1997, citado por Guimarães, 2012, p. 71) “cada coisa nada mais é que parte da unidade, do todo, mas a totalidade não é uma simples soma das partes. As partes que formam a totalidade não bastam para explicá-la. Ao contrário, é a totalidade que explica as partes". 
De acordo com Oliveira (2007), a esperança na prática da interdisciplinaridade complementa a perspectiva transversal e transdisciplinar da educação como saída para a integração das disciplinas, de seus conteúdos e outros saberes. É de extrema importância para a coletividade dos professores, na construção de projetos interdisciplinares, que esses sejam desenvolvidos em conjunto. Assim, que todos saibam sobre o tema e o que os outros professores estão trabalhando sobre o assunto.

\begin{abstract}
A interdisciplinaridade não dilui as disciplinas, ao contrário, mantém sua individualidade. Mas integra as disciplinas a partir da compreensão das múltiplas causas ou fatores que intervêm sobre a realidade e trabalha todas as linguagens necessárias para a constituição de conhecimentos, comunicação e negociação de significados e registro sistemático dos resultados (BRASIL, 1998, p. 89).
\end{abstract}

$\mathrm{Na}$ perspectiva de que o saber interdisciplinar é um elo entre o entendimento das disciplinas nas suas mais variadas áreas, a pesquisadora interviu nas sugestões que as professoras deram para um trabalho interdisciplinar e instigou que pesquisassem sobre o que é, de fato, um trabalho interdisciplinar. Assim, as professoras responderam a um questionário, no qual escreveram algumas considerações a respeito do que é um trabalho interdisciplinar.

QUADRO DE CONTEÚDO 2 - Definição de um trabalho interdisciplinar

P1 "O trabalho interdisciplinar é aquele que perpassa por todas as áreas tendo envolvimento de todos, fazendo com que haja um melhor aproveitamento e assim ações conjuntas."

P2 "Um trabalho que envolva todas as disciplinas visando um mesmo objetivo."

P3 "É um trabalho que envolve todas as disciplinas, falando e fazendo as mesmas coisas." P4 "Trabalho interdisciplinar é a interlocução entre as diferentes disciplinas que abrangem o currículo. Essa inter-relação facilita o desenvolvimento de determinados assuntos, onde, cada disciplina abrange parte do mesmo conteúdo; um complementando o outro."

Devido às respostas, notamos que as professoras trouxeram um novo olhar sobre o que é um trabalho interdisciplinar, mostrando que, ao sugerirem uma atividade interdisciplinar, elas fragmentavam as disciplinas, cada uma com seu conteúdo, mas quando a pesquisadora solicita que escrevam a definição a respeito do que seja um trabalho interdisciplinar, as professoras demonstraram, em seus discursos, uma compreensão mais integrada da interdisciplinaridade. Porém, percebe-se uma dissociação entre teoria e prática. Ressaltamos 
que, na atividade interdisciplinar, não é necessário envolver todas as disciplinas do currículo.

Com a intenção de agregar a teoria à prática, a pesquisadora passou um vídeo ${ }^{5}$ cujo título é Interdisciplinaridade e transversalidade, abordando uma discussão sobre o que é interdisciplinaridade e transversalidade, feita pelo professor Nilson José Machado, da Faculdade de Educação da USP; o vídeo mostra o exemplo de três professores de uma escola estadual de Campinas que, em parceria com a UNICAMP, escolhem o rio que corta o município como objeto de estudo, e desenvolvem, na prática, a transversalidade e a interdisciplinaridade nas áreas de geografia, língua portuguesa e química. O vídeo enfatiza a importância da participação da comunidade escolar em um projeto e como, na prática, acontece a interdisciplinaridade, na qual todas disciplinas conhecem o projeto e sabem quais são os objetivos.

Será que as propostas de inserir a educação ambiental na forma de projetos interdisciplinares e integradores, envolvendo tanto a comunidade escolar como outros segmentos ou setores da comunidade, provocaria o engajamento de todos os professores e professoras no tratamento das questões ambientais nas suas disciplinas específicas? Oliveira (2007) responde que pode ser que sim. Quando projetos dessa natureza são implementados na escola, ainda que por um pequeno grupo de professores, abre-se um caminho para pensar a inserção da dimensão ambiental na escola. A sistematização de experiências desse tipo pode permitir uma avaliação crítica e a indicação de novos caminhos a percorrer ou trilhas a serem novamente percorridas.

Ao desfragmentar as disciplinas, a interdisciplinaridade abre portas para a construção de uma nova relação com o saber; afinal, o ser humano é singular e social e, ao longo da vida, produz sentidos e significados sobre si e o mundo. O sujeito se relaciona com o aprender e saber. Charlot (2000) enfatiza que aprender significa um conteúdo intelectual; e saber tem o significado mais amplo. Existem várias formas de aprender: pode ser adquirir um saber (aprender Fisiologia, Biologia), dominar um objeto ou uma atividade (aprender a escrever, a jogar lixo na lixeira), entrar em formas relacionais (aprender a cumprimentar, a mentir). Nesse contexto, o aprender não fica restrito à obtenção do conteúdo intelectual, mas abrange todas as relações que o sujeito estabelece para adquiri-lo. Assim, quando Charlot (2000) explora a relação com o saber, ele amplia essa noção para uma relação com o aprender.

Após a intervenção, foi proposto que as professoras juntas esboçassem uma atividade interdisciplinar sobre as nascentes. A intervenção nesse contexto se amplia na busca de novas estratégias que possam favorecer a reconstrução da prática pedagógica do professor (PRADO; MARTINS, 1998).

Com isso, a intervenção é de grande valia na formação continuada dos professores, pois observamos que a intervenção da pesquisadora propiciou às professoras momentos de reflexão sobre a interdisciplinaridade e proporcionou um envolvimento de todas as professoras, uma vez que, nas anotações do 
Diário de Campo e nas transcrições, detectamos a voz de todas as professoras dando opiniões e sugestões na construção da proposta. Algumas falas, durante a construção da atividade interdisciplinar, trazem indícios disso:

QUADRO DE CONTEÚDO 3 - Construção da atividade interdisciplinar

P1: Eu penso assim, primeiro a gente ter um dia de mobilizar todo mundo a respeito da conscientizaça da importância das nascentes.

P3: Pois é, esse primeiro momento de estar conscientizando, no caso, poderia depois ta fazendo um folder para eles estarem repassando isso para escola.

P2: Para chamar a atencão mesmo do problema, para não ficar só no esquecimento.

E como atividade final, elas escreveram:

QUADRO DE CONTEÚDO 4 - Elaboração da atividade interdisciplinar

P1, P2, P3 e P4 "A atividade iniciará com um dia de mobilização onde será trabaIhado com comunidade escolar o tema Nascente. Assim, envolvemos todos com intuito de fazer com que eles se sintam parte do tema. Nesse momento, baverá uma palestra, em que será abordada a importaincia das nascentes, a necessidade de preservá-las e conservá-las e a atual situacão das nascentes em Lavras. A atividade interdisciplinar pretende ter como produto final a construcão de um folder que possa ser disponibilizado para comunidade escolar. Após, as disciplinas terem conhecimento do assunto, as mesmas dentro de seus conteúdos irão trabalhar o tema".

Notamos que, durante a elaboração da atividade, houve o envolvimento de todas as professoras, ao contrário do que ocorreu no primeiro momento, quando foi questionada a possibilidade de realizar uma atividade interdisciplinar e apenas duas professoras responderam, dando sugestões. Nesse momento, percebemos um maior envolvimento e interesse na construção de uma atividade interdisciplinar, quando, juntas, descreveram a atividade. Isso pode ser devido ao fato da construção de um novo conhecimento, do qual agora se apropriaram do que é interdisciplinar. De acordo com Guimarães (2012, p. 145),

$\mathrm{Na}$ constituição de um ambiente educativo de caráter crítico, a construção do conhecimento busca superar a visão disciplinar, elaborando uma nova interação ampliada da realidade, que alcance a interdisciplinaridade e uma melhor visão do todo. 
Afinal, para que ocorra a interdisciplinaridade, não se trata de eliminar as disciplinas, mas de torná-las comunicativas entre si, concebê-las como processos históricos e culturais, tornando necessária a atualização quando se refere às práticas do processo de ensino-aprendizagem. É compreender, entender as partes de ligação entre as diferentes áreas de conhecimento, unindo-se para transpor algo inovador, abrir sabedorias, resgatar possibilidades e ultrapassar o pensar fragmentado, na busca constante de investigação, na tentativa de superação do saber.

Segundo Tardif (2005), quando questionamos os professores sobre o seu saber, eles se referem a conhecimentos e a um saber-fazer pessoais, falam dos saberes curriculares, dos programas e dos livros didáticos, apoiam-se em conhecimentos disciplinares relativos às matérias ensinadas, fiam-se em sua própria experiência e apontam certos elementos de sua formação profissional. Em suma, o saber dos professores é plural, compósito, heterogêneo, porque envolve, no próprio exercício do trabalho, conhecimentos e um saber-fazer bastante diversos, provenientes de fontes variadas e, provavelmente, de natureza diferente.

Segundo Oliveira (2007), precisamos investigar e refletir mais sobre o caráter das iniciativas que vêm sendo implementadas nas escolas brasileiras, o que poderá trazer ainda mais luz e inspiração para pensarmos estratégias de ambientalização da escola e da sociedade. Cabe a nós, também, trabalhar para que as iniciativas no campo das políticas públicas, comprometidas com a implementação das mudanças necessárias na formação inicial e continuada de professores e professoras e da introdução de inovação nos currículos escolares, possam ser aceleradas para valorizar e manter as experiências bem-sucedidas em curso, realizadas com criatividade e perseverança por muitas professoras e professores, em muitos cantos do Brasil.

\section{Pertencimento}

Essa categoria emergiu do maior envolvimento e participação das professoras nos encontros de formação. Segundo Chizzotti (2006, citado por MOZZATO; GRZYBOVSKI, 2011), o objetivo da análise de conteúdo é compreender criticamente o sentido das comunicações, seu conteúdo manifesto ou latente, as significações explícitas ou ocultas. De acordo com esse objetivo e por meio das leituras dos textos desta pesquisa, conseguimos obter a categoria pertencimento, devido à apropriação do tema, ao envolvimento com o projeto, à maior participação das professoras ao longo dos encontros e ao interesse em desenvolver a atividade que elaboraram.

De acordo com Sousa (2010, p. 34), o sentimento de pertencimento "traduz de forma visível, em sentidos e motivações diversos dos de suas raízes, sustentando a busca de participação em grupos, tribos e comunidades que possibilitem enraizamento e gerem identidade e referência social".

Ao longo dos encontros, pelas anotações do Diário de Campo e transcrições, foi possível identificar a maior participação das professoras. Nos primeiros encontros, apenas duas professoras participavam dando sugestões; no decorrer dos encontros, todas as professoras começaram a participar, questionando e dando sugestões. Outro fator importante observado nas falas foi o interesse para que, de fato, a atividade inter- 
disciplinar elaborada por elas acontecesse.

QUADRO DE CONTEÚDO 5 - Interesse pela realização da atividade

P4: E quem é que vai buscar as palestras e esses recursos?

P3: O Bernardo de português tem uma página na coluna de Lavras será que ele podia tá ajudando com alguma coisa, ele escreve muita coisa.

P1: Isso pra quando?

P4: Antes das férias?

Isso mostra um maior envolvimento e pertencimento ao projeto. Santos (2010) corrobora, afirmando que, ao exercitar o trabalho em equipe, os professores transformam coletivamente dificuldades em desafios, superando limitações que pareciam inicialmente intransponíveis, bem como descobrem seu potencial para a criação de novidades didáticas.

Para Nóvoa (2009), é necessário devolver a formação de professores aos professores, porque o reforço de processos de formação baseados na investigação só faz sentido se eles forem construídos dentro da profissão. Enquanto forem apenas injunções do exterior, serão bem pobres as mudanças que terão lugar no interior do campo profissional docente.

Esse processo de uma maior participação das professoras, no decorrer dos encontros de formação, corrobora a terceira concepção de Cochran-Smith e Lytle (1999), segundo a qual o conhecimento da prática mostra que o professor, no decorrer de sua vida, tem papel central e crítico na geração de conhecimento sobre a prática. Ambientes nos quais os professores e outros somam esforços para construir conhecimento são de grande valia para o aprendizado do professor na geração de saberes.

A participação no processo de formação também mostra como se deu a apropriação do tema e a relação com o saber, como quando uma professora comenta que um aluno não sabia o que era nascente e que ela explicou a importância da nascente. Nesse momento, a pesquisadora enfatiza o saber do professor vinculado à sua disciplina; com isso, uma professora comentou também não conhecer algumas informações sobre as nascentes:

QUADRO DE CONTEÚDO 6 - Desconhece maiores informações sobre as nascentes

P2: Nem isso en sabia 
Segundo Reigota (2007), a temática ambiental está associada às disciplinas escolares Ciências, Biologia e Geografia. É necessário desfragmentar os conteúdos e reunir as informações dentro de um mesmo contexto, nas várias disciplinas, no intuito de relacionar os saberes. Isso mostra a importância da formação de professores que promova a troca de informações entre os docentes e a comunidade escolar. Assim, todos poderão discutir e refletir sobre as questões ambientais.

Nesse contexto, a educação ambiental crítica, contrária à educação tradicional, "volta-se para uma ação reflexiva (teoria e prática - práxis) de intervenção em uma realidade complexa”. Ou seja, é uma educação construída por todos, sendo coletiva. "Seu conteúdo está além dos livros; está na realidade socioambiental derrubando os muros das escolas" (GUIMARÃES, 2012, p. 87).

Outro momento nos encontros que mostrou a apropriação do tema e a relação do saber na participação do processo de formação, foi quando a pesquisadora solicitou que as professoras escrevessem uma justificativa e objetivos para a atividade interdisciplinar. As professoras elaboraram justificativa e objetivos, demonstrando maior compreensão do tema.

\section{QUADRO DE CONTEÚDO 7 - Maior participação das professoras}

P4: Na justificativa a gente tem que expor o que é de real que acontece, então diante da realidade, qual a realidade que eles colocaram para nós.

P1: Que as nascentes estão todas degradadas e precisam urgente ser conservadas

P4: E a falta de água que éo principal

P1: Então vamos lá. Primeiro então, diante da crise da água, da situacão atual que encontra as nascentes de Lavras, da nossa cidade, e da escassez da água, surgiu à necessidade de envolver a comunidade escolar para alertar sobre a importância da preservacão e conservacão das nascentes de Lavras. No objetivo geral a gente pode ta pegando aqui mobilizacião de toda comunidade escolar para preservar um bem património de todos. Ai os especifficos vai ser, vamos colocar assim, envolver a commidade escolar em atividades que alertam.

P3: Valorizem a importancia das nascentes.

P1: Não. Atividades que, mas primeiro P2 vamos colocar eles como sendo partes do processo então, envolver a comunidade escolar em atividades que sejam conscientizadoras, pode ser?

P3: Eu queria colocar assim que está tão perto e próximo focando conbecer esse património natural tão próximo e deles.

P4: Pertencentes a sua comunidade. 
Isso enfatiza que a educação se dá na relação com o aprendizado de um novo conhecimento e na troca de informações. Segundo Charlot (2000), toda a relação com o saber, como relação de um sujeito com seu mundo, é relação com o mundo e com uma forma de apropriação do mundo: toda relação com o saber apresenta uma dimensão epistêmica. Mas qualquer relação com o saber comporta também uma dimensão de identidade: aprender faz sentido por referência à história do sujeito, às suas expectativas, às suas referências, à sua concepção da vida, às suas relações com os outros, à imagem que tem de si e a que quer dar de si aos outros.

Esse saber plural, proveniente de fontes variadas, que reforça a relação dos saberes com diferentes atores, é reforçado na fala das professoras durante a elaboração da atividade sobre as nascentes.

QUADRO DE CONTEÚDO 8 - Envolvimento da sociedade

\begin{tabular}{|l|}
\hline \\
P1: É. Dia de mobilização e aí com uma palestra com alguém que tenha co- \\
nhecimento sobre o assunto \\
P2: E talver até mesmo a Copasa mesmo né \\
P3: ... história vem com depoimentos, fonte oral, pelo menos de quem é daqui e co- \\
nhece as nascentes que saiba, que vai montar essa história pra gente
\end{tabular}

Percebe-se que as professoras, na elaboração da atividade interdisciplinar, buscaram envolver os saberes da sociedade sobre as nascentes, quando sugeriram depoimentos orais de moradores do bairro sobre as nascentes e, ao mesmo tempo, almejaram iniciar com um dia de mobilização para toda a comunidade escolar, para o qual propõem alguém que tenha conhecimento sobre o assunto para assim darem início à atividade e para todos os envolvidos conhecerem melhor o tema que será abordado na atividade interdisciplinar.

Acreditamos que, ao traçarem essa metodologia, as professoras estejam se baseando na educação ambiental crítica, com o intuito de compreender a realidade socioambiental local por meio dos moradores que possam relatar sobre a situação das nascentes no passado e atualmente. Também almejamos que elas tenham se apropriado da EA crítica e emancipatória, quando demonstraram interesse por alguém que tenha conhecimento sobre o assunto. Assim, toda a comunidade escolar pode problematizar e questionar a importância das nascentes. Com isso, a atividade interdisciplinar não será fragmentada onde somente disciplinas ligadas ao tema, como Geografia e Biologia, conheçam sobre as nascentes.

$\mathrm{Na}$ atividade interdisciplinar construída pelas professoras, é possível 
verificar traços de uma Educação Ambiental Conservadora, na qual a atividade ainda tem traços de transmissão de conhecimentos sobre o tema abordado na pesquisa, por exemplo, quando propõem a construção de um folder para ser disponibilizado para a comunidade, o qual irá explicar os termos técnicos e a maneira correta de recuperar, preservar e recuperar as nascentes.

É importante salientar trabalhos dessa natureza que tratem a formação do professor visando desconstruir uma postura antropocêntrica e individualista da dominação do ser humano sobre a natureza.

A construção de uma Educação Ambiental crítica se faz ao longo do processo de formação, problematizando e questionando por que desenvolver atividades interdisciplinares sobre as nascentes, e isso aparece em um dos objetivos específicos escritos pelas professoras: "incentivar os jovens alunos a estar envolvidos, transformando a realidade atual".

A construção da identidade da Educação Ambiental crítica se dá mediante as relações que se estabelecem com o saber e com os outros. É necessário desenvolver projetos de EA que transcendam os limites da escola, que envolvam toda a sociedade, que proporcionem momentos de reflexão. Observamos, durante os encontros que, ao questionar quais projetos as professoras desenvolveram na escola, uma professora citou o PEAS (Programa de Educação Afetivo-Sexual) ${ }^{7}$, e três professoras citaram Coleta Seletiva.

Dentro do projeto de Coleta Seletiva, uma das atividades foi coletar o lixo do entorno da escola. Mas comentaram sobre a dificuldade da execução do projeto, pois, em alguns pontos do bairro, onde a escola está inserida, o caminhão do lixo não passa.

Isso reflete a necessidade do envolvimento da sociedade nos projetos desenvolvidos pela escola; mostra a necessidade de educação crítica, que discuta o papel do poder público nesse ambiente; que mobilize uma educação política sobre a situação; que mostre a problemática da sociedade consumista na qual vivemos e que cada vez gera mais lixo.

É necessário continuar desenvolvendo atividades que priorizem as questões ambientais, mas as atividades não podem ser meramente transmissoras de conhecimento, como práticas ligadas ao lixo, que visam ensinar o local adequado de se jogar o lixo. É necessário trabalhar com uma Educação Ambiental crítica, que vise à emancipação e transformação da sociedade.

Segundo Guimarães (2012, p. 98), entre os professores, assim como na sociedade, em geral, predominam posturas pouco críticas, levando-os a reproduzir, em suas ações, o discurso dominante, conservador, refletindo-se em práticas ingênuas, apesar de bem-intencionadas.

Essa discussão subsidia a intenção dessa pesquisa de elaboração de uma atividade interdisciplinar, pois mostra a realidade dos projetos desenvolvidos na escola. Com isso, espera-se que, além de desfragmentar as disciplinas na construção do projeto, a atividade tenha um olhar da Educação Ambiental Crítica, onde se espera que os professores, ao desenvolver a atividade, modifi- 
quem a relação com esses saberes, e não apenas transmitam a importância das nascentes, mas instiguem a comunidade escolar a problematizar e questionar as ações desenvolvidas em prol da preservação, conservação e recuperação das nascentes urbanas do município de Lavras.

\section{CONSIDERACְ̃̃ES FINAIS}

Apresentamos as considerações finais, tomando como referência as relações entre a Educação Ambiental e a formação de professores. Para isso, buscamos alguns comentários finais sobre as elaborações produzidas por professoras da escola da rede pública estadual ao participarem da construção de um projeto cujo tema articulador é um problema socioambiental local, que abre-nos possibilidades de reflexões, constatações e descobertas.

Ao longo da pesquisa, alcançamos o objetivo em relação ao qual desenvolvemos e analisamos o trabalho compartilhado com quatro professoras, tratando de questões socioambientais locais, com foco na conservação e preservação de nascentes. O desenvolvimento da pesquisa permitiu construir uma atividade interdisciplinar que visou contribuir para o processo de conscientização e constituição de identidades e responsabilidades individuais e coletivas na Escola e na comunidade escolar.

Notamos como a relação com os saberes docentes, estabelecida por um processo de formação compartilhada de professores, torna a construção de práticas de Educação Ambiental mais significativa, pois possibilita a apropriação do tema sob diferentes aspectos disciplinares e sociais e desperta o interesse e a necessidade para que a atividade por eles elaborada aconteça. Isso reflete nos atuais projetos de Educação Ambiental que não são construídos pela comunidade escolar e são simplesmente inseridos na escola como uma imposição, isto é, prontos. Assim, os sujeitos envolvidos não pertencem ao projeto e, em muitas situações, esse não condiz com a realidade local. Nessas condições, a relação que se estabelece com o saber docente é artificial e produz práticas pouco significativas, com a possibilidade de apropriações conceituais e metodológicas distorcidas.

Observamos uma maior interação dos professores com o tema da pesquisa, quando eles se apropriaram e relacionaram o tema com a problemática socioambiental local.

A Educação Ambiental, no contexto escolar, está ligada diretamente à formação inicial e continuada dos professores, não sendo possível exigir e esperar que os docentes trabalhem com uma Educação Ambiental que seja crítica, emancipatória e transformadora se os próprios professores não vivenciaram essa educação durante sua formação. Por isso, é de suma importância processos de formação continuada desenvolvidos no conhecimento da prática. Nessa perspectiva, o conhecimento é construído na relação entre a universidade e os professo- 
res, ou seja, os professores pesquisam para a construção de conhecimento e relacionam os saberes produzidos e estabelecidos ao longo da vida - isso tem papel fundamental em sua formação.

Acreditamos na necessidade de uma formação continuada, na qual o professor tem um papel fundamental no seu desenvolvimento. Isso reflete quando identificamos como se desenvolvem as interações dos sujeitos em um processo orientado por ações interdisciplinares, pois notamos, nesta pesquisa, que os professores definiam que atividade interdisciplinar era quando cada professor na sua área de conhecimento desenvolvia uma parte da atividade dentro da sua disciplina. Assim, quando as professoras pesquisaram, receberam e trocaram informações sobre o que se espera da interdisciplinaridade, foi possível verificar uma relação com os saberes construídos ao longo dos encontros, refletindo uma maior interação entre as participantes da pesquisa na elaboração da atividade interdisciplinar.

Fica assim explícita a necessidade de refletirmos sobre a formação docente e, mais ainda, sobre a formação continuada que aborde questões como interdisciplinaridade na Educação Ambiental, que vem acontecendo nas escolas devido à obrigatoriedade estabelecida nos Parâmetros Curriculares Nacionais e pela Lei 9.795 de 27 de abril de 1999 (Política Nacional de Educação Ambiental) que explana que a EA não pode estar no ambiente escolar como disciplina, pois as questões ambientais devem ser trabalhadas de forma interdisciplinar.

Questionamos até que ponto existe o (re)conhecimento dessa lei por parte dos professores, pois já se passaram mais de dez anos desde a sua criação. Tal legislação ainda carece de fortalecimento, representatividade e interesse por parte dos órgãos públicos em consolidá-la, efetivamente, nas diversas modalidades de ensino.

Com a discussão a respeito da interdisciplinaridade em atividades de Educação Ambiental, tivemos a intenção de subsidiar e analisar a produção e o desenvolvimento de atividades que contribuam com o processo de conscientização da comunidade escolar sobre a importância e recuperação/conservação/preservação das nascentes urbanas. A pesquisa alcançou o objetivo sobre a construção da atividade interdisciplinar com as professoras que participaram, mas o desenvolvimento da atividade na escola da rede pública estadual ficou sob a responsabilidade do Projeto AJA. Refletimos aqui a necessidade da discussão da atividade final com toda a comunidade escolar, para não cometermos uma prática errônea que é o desenvolvimento de projetos que já chegam prontos à escola. Apesar de a atividade ter sido elaborada por quatro professoras da escola, é importante o envolvimento de todos os professores, para que possam pertencer ao tema e à atividade - isso poderá abrir caminho para modificações na proposta estabelecida por essas quatro professoras.

Por fim, enfatizamos a importância do elo entre a Educação Ambien- 
tal e a formação de professores; essa associação reflete a possibilidade de que os professores se apropriem da temática ambiental, superando assim a cultura de transmissão de conhecimentos estabelecida na sala de aula.

\section{NOTAS}

1"Por elaborações entendemos as manifestações do pensamento sobre os conceitos quer orais ou escritas" (MOURA, 1995). CONFERIR DATA. NA SEÇÃO REFERENCIAS CONTA APENAS OBRA DE 1995.

${ }^{2}$ Em razão de o tempo de captação dos dados no mestrado ser bastante reduzido para uma imersão na escola, que gere um fluxo contínuo de trabalho a ponto de realizar uma pesquisa-ação.

${ }^{3}$ Cabe ressaltar que o módulo II é institucionalizado nas escolas públicas estaduais como um horário para trabalhos pedagógicos destinados à promoção do diálogo, planejamento de atividades, avaliações e reflexões sobre práticas educativas, troca de saberes e experiências entre professores (CERATI; LAZARINI, 2009).

${ }^{4}$ Cf. COCHRAN-SMITH; LYTLE, 1999; PLACCO; SOUZA, 2006.

5Disponível em: <https://www.youtube.com/watch?v=cNpTwye78Vk>. Acesso em: 12 abr. 2013.

${ }^{6} \mathrm{Na}$ elaboração final da atividade interdisciplinar, foi possível verificar a participação de todas as professoras.

${ }^{7}$ O PEAS foi implementado em 2000, a partir de metodologia desenvolvida pela Fundação Odebrecht em parceria com o Governo do Estado de Minas Gerais.

\section{REFERÊNCIAS}

BARDIN, L. Análise de conteído. Lisboa: Edições 70, 2008. 288 p.

BRASIL. Lei $n^{\circ}$ 9.795, de 27 de abril de 1999. Institui a Política Nacional de Educação Ambiental. Brasília, 1999. Disponível em: < http://www.planalto.gov.br/ccivil_03/leis/19795.htm> Acesso em: 10 ago. 2014.

BRASIL. Ministério da Educação. Secretaria de Educação Fundamental. Parâmetros Curriculares Nacionais: $3^{\circ}$ e $4^{\circ}$ ciclos: apresentação dos temas transversais. Brasília, 1998. 436 p.

CARVALHO, I. C. M. A invenção do sujeito ecológico: identidades e subjetividade na formação dos educadores ambientais. In: SATO, M.; CARVALHO, I. C. M. (Org.). Educação ambiental: pesquisa e desafios. Porto Alegre: Artmed, 2005. p. 51-63.

CERATI, T. M.; LAZARINI, R. A. de M. A pesquisa-ação em educação ambiental: uma experiência no entorno de uma unidade de conservação urbana. Ciência e Educação, Bauru, v. 15, n. 2, p. 383-392, 2009. 
CHARLOT, B. Da relação com o saber: elementos para uma teoria. Porto Alegre: Artmed, 2000. 93 p.

COCHRAN-SMITH, M.; LYTLE, S. L. Relationships of knowledge and practice: teacher learning in communities. Review of Research in Education, Chicago, v. 24,

p. 249-305, 1999.

FRANCO, M. L. P. B. Análise de conteúdo. 2. ed. Brasília: Líber Livros, 2005. 72 p.

GOLDENBERG, M. $A$ arte de pesquisar: como fazer pesquisa qualitativa em ciências sociais. Rio de Janeiro: Record, 1999. 107 p.

GUIMARÃES, M. Educação ambiental crítica. In: LAYRARGUES, P. P. (Org.). Identidades da educação ambiental brasileira. Brasilia: MMA, 2004. p. 24-34.

GUIMARÃES, M. Formação de educadores ambientais. 8. ed. Campinas: Papirus, 2012. 171 p.

LONGAREZI, A. M.; SILVA, J. L. da. Interface entre pesquisa e formação de professores delimitando o conceito de pesquisa-formação. EDUCERE. 2008 Disponível em: <http://www.pucpr.br/eventos/ educere/educere2008/anais/

pdf/157_187.pdf> Acesso em: 4 ago. 2014.

LOUREIRO, C. F. B. Educação ambiental crítica: contribuições e desafios. In: MELLO, S. S. de; TRAJBER, R. (Org.). Vamos cuidar do Brasil: conceitos e práticas em educação ambiental na escola. Brasília: MEC/UNESCO, v. 1, 2007. p. 65-71.

LOUREIRO, C. F. B. Educação ambiental e movimentos sociais na construção da cidadania ecológica e planetária. In: LOUREIRO, C. F. B.; LAYRARGUES, P. P.; CASTRO, R. S. de (Org.). Educação ambiental: repensando o espaço da cidadania. 3. ed. São Paulo: Cortez, 2005. p. 69-98.

LOUREIRO, C. F. B. Trajetória e fundamentos da educacão ambiental. São Paulo: Cortez, 2004. 150 p.

MOURA, A. R. L. de. A medida e a criança pré-escolar. 1995. 221 f. Tese (Doutorado em Educação) - Universidade Estadual de Campinas, Campinas, 1995.

MOZZATO, A. D.; GRZYBOVSKI, D. Análise de Conteúdo como técnica de análise de dados qualitativos no campo da administração: potencial e desafios. RAC, Curitiba, v. 15, n. 4, p. 731-747, 2011.

NÓVOA, A. Para uma formação de professores construída dentro da profissão. 2009. Disponível em: < http:/ /www. revistaeducacion.mec.es/re350/re350_09por.pdf> Acesso em: 4 fev. 2014.

OLIVEIRA, H. T. de. Educação ambiental: ser ou não ser uma disciplina: essa é a principal questão?! In: MELLO, S. S. de; TRAJBER, R. (Org.). Vamos cuidar do Brasil: conceitos e práticas em educação ambiental na escola. Brasília: MEC/UNESCO, v. 1, 2007. p. 103-114.

PLACCO, V. M. N.; SOUZA, V. L. T. (Org.). Aprendizagem do adulto professor. São Paulo: Loyola, 2006.96 p.

PONTALTI, E. S. Projeto de Educação Ambiental: Parque Cinturão Verde de Cianorte. 2005???. Disponível em: <http://www.apromac.org.br>. Acesso em: 20 set. 2013.

PRADO, M. E. B.; MARTINS, M. C. A formação do professor: estratégias de intervenção no processo de reconstrução da prática pedagógica. In: CONGRESSO DA RIBIE - REDE IBEROAMERICANA DE INFORMÁTICA EDUCATIVA, 4., 1998, Brasilia. Anais... Brasilia: RIBIE, 1998. 1 CD-ROM.

REIGOTA, M. O estado da arte da pesquisa em Educação Ambiental no Brasil. Pesquisa em Educação Ambiental, Rio Claro, v. 2, n. 1, p. 33-66, jan./jun. 2007.

REIGOTA, M. O que é educação ambiental. 2. ed. São Paulo: Brasiliense, 2009.

$107 \mathrm{p}$.

ROSA, I. M. C. O meio ambiente como tema transversal na escola: limites e desafios. In: ENCONTRO

NACIONAL DE DIDÁTICA E PRÁTICA DE ENSINO, 1., 2003, Goiânia. Anais... Goiânia: EN- 
DIPE, 2003. 1 CD-ROM.

SANTOS, E. O. dos. Educação online: cibercultura e pesquisa-formação na prática docente. 2005. 351 p. Tese (Doutorado em Educação) - Universidade Federal da Bahia, Salvador, 2005.

SANTOS, G. F. dos. Para ambientalista, situação de abandono de nascentes na área urbana de Lavras preocupa. Lavras 24 horas, Lavras, 15 ago. 2013. Disponível em <http:/ /www.lavras24horas.com.br/ portal/para-ambientalista-situacao-de-abandono-de-nascentes-na-area-urbana-de-lavras-preocupa/> Acesso em: 15 ago. 2013.

SANTOS, V. M. N. dos. Formação de professores para o estudo do ambiente: realidade socioambiental local e cidadania. In: TRISTÃO, M.; JACOBI, P. R. (Org.). Educação ambiental e os movimentos de um campo de pesquisa. São Paulo: Annablume, 2010. p. 241-262.

SANTOS, V. M. N. dos; COMPIANI, M. Formação de professores: desenvolvimento de projetos escolares de educação ambiental com o uso integrado de recursos de sensoriamento remoto e trabalhos de campo para o estudo do meio ambiente e exercício da cidadania. In: ENCONTRO NACIONAL DE PESQUISA EM EDUCAÇÃO EM CIÊNCIAS, 5., 2005, Bauru. Anais... Bauru: ABRAPEC, 2005. 1 CD-ROM.

SATO, M. Educaşão para o ambiente amazônico. 1997. 246 f. Tese (Doutorado em Ecologia e Recursos Naturais) - Universidade Federal de São Carlos, São Carlos, 1997.

SOUSA, M. W. de. O pertencimento ao comum mediático: a identidade em tempos de transição. Revista Significação, São Paulo, n. 34, p. 31-52, 2010. Disponível em: <http://www.usp.br/significacao/pdf/ Significacao34_2\%20Mauro\%20Wilton\%20de\%20Sousa.pdf> Acesso em: 1 nov. 2014.

TARDIF, M. Saberes docentes e formação profissional. Petrópolis: Vozes, 2005.

$328 \mathrm{p}$.

THIOLLENT, M. Metodologia da pesquisa-ação. 14. ed. São Paulo: Cortez, 2005. 136 p.

THIOLLENT, M. Notas para o debate sobre pesquisa-ação. In: BRANDÃO, C. R. (Org.). Repensando a pesquisa participante. São Paulo: Brasiliense, 1985. p. 82-103.

TOZONI-REIS, M. F. C. Pesquisa-ação: compartilhando saberes: pesquisa e ação educativa ambiental. In: FERRARO JÚNIOR, L. A. (Org.). Encontros e caminhos: formação de educadoras (es) ambientais e coletivo educadores. Brasília: Ministério do Meio Ambiente, 2005. Disponível em: <http://mma.gov. br/port/sdi/ea/og/pog/arqs/ encontros.pdf>. Acesso em: 12 abr. 2013.

Data do recebimento: 19/02/2015

Data de aprovação: 30/10/2015

Data da versão final: 05/11/2015

\section{Contato:}

Catarina Teixeira

Universidade Federal do Triângulo Mineiro

Instituto de Ciências Exatas, Naturais e Educação Av. Dr. Randolfo Borges, 1400

UniverdecidadeCEP: 38.064-200 - Uberaba-MG 